\title{
金属硫蛋白对大鼠肝脏溶酶体膜 稳定性的影响
}

\author{
唐朝枢 李兆萍 苏静怡 程 时* \\ (北京医科大学病理生理教研室,*生物物理教研空)
}

\section{关钱调金属硫蛋白、溶酶体、缺氧}

机体在中毒、感染、创伤、炎症、辐射等应激情况下,金属硫蛋白 (Metallothionein, MT)合 成显著增加,近年大量实验资料提示 $\mathrm{MT}$ 可能参与机体抗损伤的第一线防御功能 ${ }^{[1]}$, 但其作 用机理尚不清楚. 本工作观察 MT 对大鼠肝肚缺氧灌流和离体溶酶体缺氧摡育时溶酶体膜 稳定性的影响,以探讨 MT 的细胞保护机理.

\section{一、材料和方法}

$200-250 \mathrm{~g}$ 雄性 Sprague-Dawley 大鼠,术前禁食 $18 \mathrm{~h}$.

1. 大鼠肝琏缺满灌流 $20 \%$ 乌拉坦 $5 \mathrm{ml} / \mathrm{kg}$ 腹腔注射麻醉, $0.3 \%$ 肝素 $2 \mathrm{ml} / \mathrm{kg}$ 股静脉 注射抗凝血, 门静脉插管接蠕动京 (Masterflex) 以 $30 \mathrm{ml} / \mathrm{min}$ 恒流灌注 $37^{\circ} \mathrm{C} \mathrm{Krebs-}$ Henseleit $(\mathrm{KH})$ 液, 下腔静脉插管收集灌流液. 对照组 $(n=8): \mathrm{KH}$ 液与 $95 \% \mathrm{~N}_{2}-5 \%$ $\mathrm{CO}_{2}$ 平衡 $\left(\mathrm{PO}_{2}<15 \mathrm{mmHg}\right)$, MT 组 $(n=8)$ : 无氧灌流的 $\mathrm{KH}$ 液含 $10^{-5} \mathrm{~mol} / 1 \mathrm{MT}$ (兔 肝 MT, MW6000, Sigma Co). 另取 4 只大鼠为不缺氧组, $\mathrm{KH}$ 液与 $95 \% \mathrm{O}_{2}-5 \% \mathrm{CO}_{2}$ 平 衡 $\left(\mathrm{PO}_{2}>550 \mathrm{mmHg}\right)$. 灌流 $60 \mathrm{~min}$ 后结束实验,测定此时收集的灌流液中溶酶体酶组织蛋 白酶 D (Cathepsin D, CD) 活性,表示肝胜释放的 $C D$. 取出肝腔于 $4^{\circ} \mathrm{C} \quad 0.25 \mathrm{~mol} / 1$ 蔗糖 液用玻璃匀浆器制成 $20 \%(W / V)$ 肝匀浆. 差速离心分离肝溶酶体 ${ }^{[2]}: 1200 \mathrm{~g} 4^{\circ} \mathrm{C}$ 离心 15 $\mathrm{min}$, 取上清于 $18000 \mathrm{~g} 4^{\circ} \mathrm{C}$ 再离心 $20 \mathrm{~min}$. 测定上清 $\mathrm{CD}$ 活性表示从溶酶体膜漏出到胞浆 的游离 $\mathrm{CD}$; 沉淀部分(即溶酶体)加人 $0.1 \%$ Triton $\mathrm{X}-10037^{\circ} \mathrm{C}$ 师䒾 $20 \mathrm{~min}$ 后测定其 $\mathrm{CD}$ 活性, 表示溶酶体内结合的 $\mathrm{CD}$. 上清 $\mathrm{CD} /($ 上清 $\mathrm{CD}+$ 沉淀 $\mathrm{CD}$ )表示 $\mathrm{CD}$ 从溶酶体膜漏 出率 (\%). 改良 Anson 法测定 CD 活性 ${ }^{[3]}$ : 牛血红蛋白 (Sigma Co) 为酶底物, 酶活性用 国际单位 $\mathrm{U} / \mathrm{mg}$ 蛋白表示. Lowry 法蛋白质定量. 结果用均数士标准误表示, 方差分析 $q$ 检测作统计学处理.

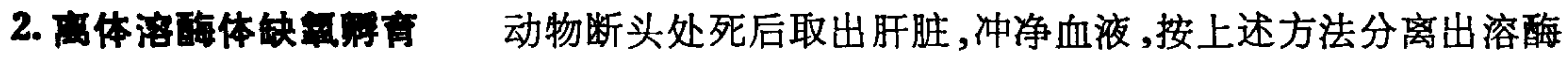
体,悬浮于 $\mathrm{KH}$ 液约 $8 \mathrm{mg}$ 蛋白 $/ \mathrm{ml}, 4^{\circ} \mathrm{C}$ 静置 $15 \mathrm{~min}$ 后分置于下述各硅化处理过的试管中 ( $1 \mathrm{ml} /$ 管)， 1 号管为未摡育管: 立即测定 $\mathrm{CD}$ 活性. 2 号管为对照管: 在恒温水浴振荡器 上 $37^{\circ} \mathrm{C}$ 缺氧睬育 $\left(95 \% \mathrm{~N}_{2}-5 \% \mathrm{CO}_{2}\right) 30 \mathrm{~min}$, 以下各管释育条件相同. 3-5 号管分别含

本文 1988 年 9 月 1 日收到。 
MT $10^{-4}, 10^{-5}, 10^{-6} \mathrm{~mol} / 1$ 共同睬育. 6 号管含牛血清白蛋白（Factor V, MW 45000, Sigma Co ) $10^{-4} \mathrm{~mol} / 1.7$ 号管含地塞米松 (北京制药厂) $10^{-5} \mathrm{~mol} / 1$. 上述各管于 $4^{\circ} \mathrm{C}, 18000 \mathrm{~g}$ 离心 $20 \mathrm{~min}$ 后, 按上述方法分别测定上清和沉淀 CD 活性. 6 次实验,每次作二平行管. 实 验结果用配对资料 $t$ 检验作统计学处理.

\section{二、结 果}

1. 大鼠肝脏缺苚䔶注 (结果见表 1) 肝肚缺氧时溶酶体膜稳定性降低, 大量 CD 从溶 酶体内漏出到胞浆成为游离 $\mathrm{CD}$, 甚至漏出细胞膜进人灌流液. $\mathrm{MT}$ 显著抑制肝脏缺氧灌流 时 $\mathrm{CD}$ 漏出, $\mathrm{MT}$ 组肝脏游离 $\mathrm{CD}$ 和灌流液 $\mathrm{CD}$ 的活性都显著低于对照组.

表 1 M 对缺氧灌流肝脏的溶酶体膜稳定性的影响

\begin{tabular}{c|c|c|c}
\hline 例 & \multicolumn{1}{c|}{$\begin{array}{c}\text { 灌流液 } \mathrm{CD} \\
(\mathrm{U} / \mathrm{m} 1)\end{array}$} & $\begin{array}{c}\text { 肝肚游离 } \mathrm{CD} \\
(\mathrm{U} / \mathrm{mg} \text { 蛋白 })\end{array}$ & $\begin{array}{c}\mathrm{CD} \text { 漏出 } \\
(\%)\end{array}$ \\
\hline 8 & $4.17 \pm 0.95$ & $3.42 \pm 0.32$ & $31.27 \pm 4.17$ \\
8 & $1.63 \pm 0.41^{*}$ & $2.06 \pm 0.28^{* *}$ & $19.84 \pm 2.44^{*}$ \\
4 & $0.41 \pm 0.44^{* *}$ & $0.64 \pm 0.11^{* *}$ & $5.22 \pm 1.22^{* *}$ \\
\hline
\end{tabular}

与对照组相比较 $* P<0.5, * * P<0.01$.

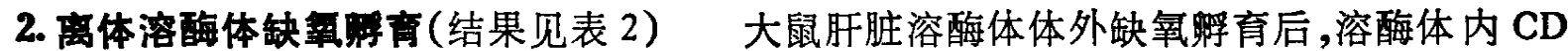
大量漏出到培养基质中成为游离 $\mathrm{CD}$, 而加人 $\mathrm{MT}$ 同时睬育显著抑制 $\mathrm{CD}$ 漏出, 其效应在本 实验浓度范围内呈剂量依赖关系。血清白蛋白也有轻度稳膜作用，但其效应远弱于 MT, $10^{-4} \mathrm{~mol} / 1$ 抑制 $\mathrm{CD}$ 漏出的作用接近 $10^{-6} \mathrm{~mol} / 1 \mathrm{MT}$ 的效应 $(P>0.2)$. 地塞米松是已知的 高效膜稳定剂，在本实验条件下 $10^{-5} \mathrm{~mol} / 1$ 地塞米松的作用略强于 $10^{-4} \mathrm{~mol} / 1 \mathrm{MT}(P<$ 0.05).

表 $2 \mathrm{MT}$ 对缺氧睬育的离体肝脏溶酶体膜稳定性影响

\begin{tabular}{|c|c|c|}
\hline & 游离 $\mathrm{CD}(\mathrm{U} / \mathrm{mg}$ 蛋白 $)$ & $\mathrm{CD}$ 漏出 (\%) \\
\hline 桴育前 & $0.53 \pm 0.11^{* *}$ & $4.72 \pm 1.07^{* *}$ \\
\hline 对䎄 & $11.59 \pm 0.67$ & $60.14 \pm 3.77$ \\
\hline $\mathrm{MT} 10^{-4} \mathrm{~mol} / 1$ & $7.85 \pm 0.54^{* *}$ & $39.72 \pm 2.27 * *$ \\
\hline MT $10^{-5} \mathrm{~mol} / 1$ & $9.56 \pm 0.62^{* *}$ & $45.63 \pm 1.88^{* *}$ \\
\hline MT $10^{-6} \mathrm{~mol} / 1$ & $10.18 \pm 0.59 *$ & $53.14 \pm 2 \cdot 57^{* *}$ \\
\hline 白蛋白 $10^{-4} \mathrm{~mol} / \mathrm{l}$ & $10.54 \pm 0.64 *$ & $55.08 \pm 3.13^{*}$ \\
\hline 地塞米松 $10^{-3} \mathrm{~mol} / 1$ & $6.12 \pm 0.58 * *$ & $31.28 \pm 2.09 * *$ \\
\hline
\end{tabular}

$n=6$, 与对照管相比较 $* P<0.05, * * P<0.01$.

\section{三、讨 论}

$\mathrm{MT}$ 是富含半胱氨酸残基和 $\mathrm{Zn} 、 \mathrm{Cd} 、 \mathrm{Cu}$ 等多种重金属离子的非酶低分子蛋白,近年发 现 MT 参与机体应激时的细胞代谢调节和适应反应 ${ }^{[4]}$. 我们以前的工作观察到 MT 能有效 地防治离体大鼠心肌细胞缺氧一复氧损伤, 但其作用机理尚不清楚 ${ }^{[3]}$. MT 参与机体抗损伤的 防御机能，不仅与其结合重金属解毒和调节 $\mathrm{Zn} 、 \mathrm{Cu}$ 细胞代谢作用有关 ${ }^{[1]}$, Thornalley 等 ${ }^{[0]}$ 发现 MT 还具有强烈清除氧自由基, 尤其是羟自由基的作用. 本实验则发现 MT 具有直接的 


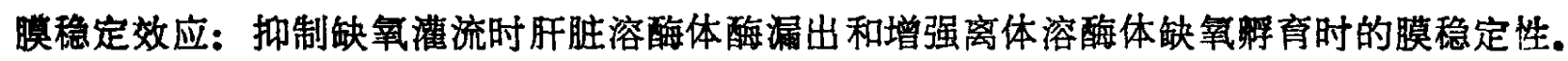
MT 的稳膜作用在本实验浓宴 $\left(10^{-6}-10^{-4} \mathrm{~mol} / 1\right)$ 呈剂量依赖关系，该剂量符合大鼠 MT 的生 理范围, 我们曾测定健康大鼠肝脏 $\mathrm{MT}$ 含量 $2.5 \pm 0.1 \mu \mathrm{g} /(\mathrm{g} \cdot \mathrm{ww})(n-8)$, 而用 $\mathrm{Zn}^{\mathrm{g}+}$ 诱导 后高达 $227.7 \pm 6.4 \mu \mathrm{g} /(\mathrm{g} \cdot \mathrm{ww})(n=8)$. 近年大量实验资料证实溶酶体膜稳定性破坏导致 溶酶体酶的瘺出,在炎症、缺血缺氧休克等许多病理过程中都具有重要的发病学意义. 从本实 验结果可以认为 MT 的稳膜作用是 MT 作为内源性抗损伤物质参与机体防御功能的重要机 理之一. 因此增加机体内源性 MT 合成或补充给予外源性 MT 可能作为防治某些疾病的重 要手段之一,值得临床和基础研究的重视。

\section{考文献}

[ 1 ] Karin, M., Cell, 41(1985), 9-10.

[ 2 ] Ferguson, W. W. et al., Am. J. Physiol., 222(1972), 450-456.

[. 3] Su, J. Y. et al., Naunyn Schmiedebergs Arch Pharmacol., 325(1984), 360-365.

[4] 程时,生理科学进展, 18(1987), 35.2-354.

[5] 本兆萍等,科学通报, 34(1989), 544--546.

[. 6] Thornalley, P. J. and Vasak, M., Biachim. Biophys. Acte, 827(1985), 36-44. 